\title{
EPR and Magnetic Studies of a Carboxylate-Bridged Dinuclear Copper(II) Compound: $\left[\mathrm{Cu}_{2}(\mathrm{flu})_{4}(\mathrm{dmf})_{2}\right]$
}

\author{
Otaciro R. Nascimento, ${ }^{*, a}$ Lia M. B. Napolitano, ${ }^{a}$ María H. Torre, ${ }^{b}$ \\ Octavio Peña ${ }^{c}$ and Rafael Calvo ${ }^{d}$
}

\author{
${ }^{a}$ Grupo de Biofísica Molecular Sergio Mascarenhas, Departamento de Física e Informática, Instituto de \\ Física de São Carlos, Universidade de São Paulo, CP 369, 13560-970 São Carlos-SP, Brazil \\ ${ }^{b}$ Química Inorgánica, Universidad de la República (UDELAR), Gral. Flores 2124, CC 1157, \\ Montevideo, Uruguay \\ 'UMR 6226 CNRS, Sciences Chimiques de Rennes, Université de Rennes 1, 35042 Rennes, France \\ ${ }^{d}$ Facultad de Bioquímica y Ciencias Biológicas, Universidad Nacional del Litoral and \\ INTEC (CONICET-UNL), Güemes 3450, 3000 Santa Fe, Argentina
}

\begin{abstract}
Reportamos neste trabalho os estudos magnéticos e de RPE do composto $\left[\mathrm{Cu}_{2}(\mathrm{flu})_{4}(\mathrm{dmf})_{2}\right]$ (flu $=$ flufenamato e $\mathrm{dmf}=$ dimetilformamida), tendo os ions $\mathrm{Cu}^{\mathrm{II}}$ como unidades dinucleares em forma de tetracarboxilato "paddle wheel". Medidas de susceptibilidade magnética na faixa de temperatura $10 \leq \mathrm{T} \leq 275 \mathrm{~K}$ permitiram a determinação da energia de interação antiferromagnética $J_{0}=-294 \pm 5 \mathrm{~cm}^{-1}$ entre os íons $\mathrm{Cu}^{\mathrm{II}}\left(\mathcal{H}_{\mathrm{ex}}=-J_{0} S_{1} \cdot S_{2}\right)$. Medidas de RPE (espectroscopia de ressonância paramagnética eletrônica) em temperatura ambiente com a amostra em pó e monocristal em bandas X e Q resultaram nos valores $\mathrm{g}_{/ /}=2.373, \mathrm{~g}_{\perp}=2.073$ e parâmetros de campo zero $\mathrm{D}=(-0.334 \pm 0.001) \mathrm{cm}^{-1}$ e E ca. 0 . Medidas com a intensidade integrada do sinal de RPE do monocristal na faixa de temperatura $40 \leq \mathrm{T} \leq 295 \mathrm{~K}$ indicaram o valor de $J_{0}=-283 \pm 5 \mathrm{~cm}^{-1}$. Um limite superior de $\left|J^{\prime}\right|<5 \times 10^{-3} \mathrm{~cm}^{-1}$ para o acoplamento de intercâmbio entre unidades dinucleares vizinhas a distâncias de $c a$. $14.24 \AA$ foi estimado com base na variação angular do espectro ao redor do ângulo mágico. Os resultados são discutidos com base na estrutura da unidade dinuclear e das ligações que conectam os íons de $\mathrm{Cu}^{\mathrm{II}}$, comparando-os com compostos similares descritos na literatura.
\end{abstract}

We report magnetic and EPR (electron paramagnetic resonance) spectroscopy studies of $\left[\mathrm{Cu}_{2}(\mathrm{flu})_{4}(\mathrm{dmf})_{2}\right]($ flu $=$ flufenamate and $\mathrm{dmf}=$ dimethylformamide $)$, which has $\mathrm{Cu}^{\mathrm{II}}$ ions in tetracarboxylate "paddle wheel" dinuclear units. Susceptibility measurements at $10 \leq \mathrm{T} \leq 275 \mathrm{~K}$ allowed the evaluation of an antiferromagnetic intradinuclear exchange coupling $J_{0}=-294 \pm 5 \mathrm{~cm}^{-1}$ between $\mathrm{Cu}^{\mathrm{II}}$ ions $\left(\mathcal{H}_{\mathrm{ex}}=-J_{0} \boldsymbol{S}_{1} \cdot \boldsymbol{S}_{2}\right)$. EPR experiments at $300 \mathrm{~K}$ in powder and single-crystals at 9.5 and $34.4 \mathrm{GHz}$ indicated $g_{/ /}=2.373, g_{\perp}=2.073$ and zero field splitting parameters $\mathrm{D}=(-0.334 \pm 0.001) \mathrm{cm}^{-1}$ and $\mathrm{E} c a$. 0 . EPR signal intensity measurements at X-band in the range $4 \leq \mathrm{T} \leq 295 \mathrm{~K}$ indicated that $J_{0}=-283 \pm 5 \mathrm{~cm}^{-1}$. A higher limit $\left|J^{\prime}\right|<5 \times 10^{-3} \mathrm{~cm}^{-1}$ for the interdinuclear exchange coupling between neighbor units at $c a .14 .24 \AA$ was estimated from the angular variation of the single crystal spectra around the magic angles. The results are discussed in terms of the structure of the dinuclear unit and the bridges connecting $\mathrm{Cu}^{\mathrm{II}}$ ions and compared with values reported for similar compounds.

Keywords: copper(II), dinuclear complex, magnetic properties, EPR spectroscopy

\section{Introduction}

Studies of copper dinuclear compounds, ${ }^{1}$ the simplest coupled magnetic systems, allow evaluating the exchange

*e-mail: ciro@if.sc.usp.br couplings between $\mathrm{Cu}^{\mathrm{II}}$ ions and correlating them with structural information for a better understanding of these couplings. These investigations provided the starting point of molecular magnetism, ${ }^{2}$ a field that strongly motivated efforts of chemists, physicists and materials scientists in the last 30 years. Magnetic measurements and electron 
paramagnetic resonance spectroscopy (EPR) are the techniques commonly employed to evaluate the exchange coupling and the zero field splitting.

A large number of dinuclear $\mathrm{Cu}^{\mathrm{II}}$ compounds with four O-C-Obridges and the classic "paddle wheel" structure, reported since the classical works of Bleaney and Bowers, ${ }^{1}$ and Guha ${ }^{3}$ on copper acetate, are found in the Cambridge Crystallographic Database. ${ }^{4}$ They may be described by the general formula $\left[\mathrm{Cu}_{2}(\mu-\mathrm{OOCR})_{4} \mathrm{~L}_{2}\right]$ with many possible $\mathrm{R}$ and $\mathrm{L}$. The exchange couplings between the metal ions depend mainly on the $\mathrm{R}$ group. The two axial ligands (L) are important for the coupling between neighbor units; when they are absent, the units tend to combine in chains or rings. ${ }^{5,6}$ The great structural diversity of the "paddle wheel" units reported over $c a .60$ years ${ }^{7}$ maintained the interest in their magnetic properties. Interesting quantum phase transitions produced by randomly distributed interactions between one unit and the "bath" of other units in the lattice have been recently observed by EPR. ${ }^{6,8}$

We report here magnetic measurements and singlecrystal and powder EPR spectra of tetrakis $\left(\mu_{2}-N-3\right.$-trifluoromethylphenylanthranilato- $O, O^{\prime}$ )-bis(dimethylformamide)-

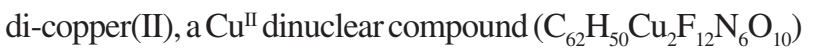
herein called $\left[\mathrm{Cu}_{2}(\mathrm{flu})_{4}(\mathrm{dmf})_{2}\right]$ (flu = deprotonated $\mathrm{N}$-3trifluromethylphenylanthranilic acid, called flufenamate, and $\mathrm{dmf}=$ dimethylformamide, see Figure $1 \mathrm{a}) .\left[\mathrm{Cu}_{2}(\mathrm{flu})_{4}(\mathrm{dmf})_{2}\right]$ crystallizes ${ }^{9}$ in the monoclinic space group $P 2_{1} / c$ with lattice parameters $a=12.727 \AA$. $b=9.263 \AA, c=26.940 \AA, \alpha=$ $\gamma=90^{\circ}, \beta=102.830^{\circ}$ and $Z=2$ molecules per unit cell (Figure 1b). The copper atoms are in an elongated octahedral environment, equatorially coordinated to four carboxylate oxygen atoms from the flu ligands with $\mathrm{Cu} \cdots \mathrm{O}$ O bond distances between 1.961 and $1.968 \AA$, and axially connected to dmf oxygen atoms at $2.129 \AA$. The four symmetry related $\mathrm{Cu}^{\mathrm{II}}$ ions in the unit cell have fractional coordinates $[\mathrm{x}, \mathrm{y}, \mathrm{z}] \equiv$ $[0.4656,0.0918,0.0298]$ and atoms at sites $(\mathbf{1}) \equiv[\mathrm{x}, \mathrm{y}, \mathrm{z}]$, (2) $\equiv[-\mathrm{x},-\mathrm{y},-\mathrm{z}],(\mathbf{3}) \equiv\left[-\mathrm{x}, 1 / 2+\mathrm{y},{ }^{1 / 2}-\mathrm{z}\right]$ and $(\mathbf{4}) \equiv[\mathrm{x}, 1 / 2-\mathrm{y}, 1 / 2+\mathrm{z}]$, with sites (1) and (3) related by inversion operations to (2) and (4), and sites (1) and (2) related by $\mathrm{C}_{2}$ rotations around $b$ to $(\mathbf{3})$ and $(\mathbf{4})$, respectively. Pairs $(\mathbf{1}+\mathbf{2})$ and $(\mathbf{3}+\mathbf{4})$ of $\mathrm{Cu}^{\mathrm{II}}$ ions at $2.619 \AA$ are bridged by four carboxylate groups from flufenamate ions giving rise to two centrosymmetrical "paddle wheel" dinuclear units A and B per unit cell, related by a $\mathrm{C}_{2}$ operation around the $b$ axis (Figure 1c).

We discuss the magnetic parameters evaluated for $\left[\mathrm{Cu}_{2}(\mathrm{flu})_{4}(\mathrm{dmf})_{2}\right]$ in terms of results reported for other dinuclear $\mathrm{Cu}^{\mathrm{II}}$ compounds showing tetracarboxylate "paddle wheel" structures with flufenamate ligands. ${ }^{10} \mathrm{An}$ upper limit for the magnitude of the exchange coupling between neighbor types A and B units at $c a .14 .24 \AA$ was obtained and compared with couplings between spins at long distances in other compounds.

\section{Experimental}

\section{Sample preparation}

The compound $\left[\mathrm{Cu}_{2}(\mathrm{flu})_{4}(\mathrm{dmf})_{2}\right]$ was prepared and crystallized as described previously. ${ }^{9}$ The single crystals are stable and display $b c$ growth faces. Powder X-ray measurements verified that the material is that previously described. ${ }^{9}$ Powder samples for magnetic and EPR measurements were prepared by finely grinding single crystals. For the single crystal EPR measurements, a $b c$ face of a crystal was glued to a face of a cleaved $\mathrm{KCl}$ cubic holder, with the $b$ direction parallel to a side of the cube (see, e.g., Figure 3 of reference 11). This holder provides a laboratory frame of axes with the crystal directions $b, c$ and $a^{*}=b \times c$ along the $\mathrm{y}, \mathrm{z}$ and $\mathrm{x}$ directions of the cube, respectively. It was mounted on top of a pedestal inside the cavity, so the spectra could be measured as a function of the orientation of the magnetic field $B_{0}=\mu_{0}$ $\mathrm{H}=\mathrm{B}_{0} \mathrm{~h}$, where $\mu_{0}$ is the permeability of the vacuum and $\mathrm{h}=(\sin \theta \cos \phi, \sin \theta \sin \phi, \cos \theta)$, at $c a .5^{\circ}$ intervals in the three crystal planes. The EPR samples included a spectrum of $\mathrm{MgO}: \mathrm{Cr}^{\mathrm{III}}(\mathrm{g}=1.9797)$ as a paramagnetic signal intensity marker.

\section{Magnetic measurements}

The magnetic susceptibility was measured with a Quantum Design MPMS XL5 Squid magnetometer. A sample containing $66.0 \mathrm{mg}$ of powdered material was packed in Teflon film having a small diamagnetic contribution, and measured in the temperature range $10 \leq \mathrm{T} \leq 275 \mathrm{~K}$, with $\mathrm{B}_{0}=200 \mathrm{mT}$.

\section{EPR measurements}

Spectra at $c a .9 .50 \mathrm{GHz}$ (X-band) and $c a .34 .4 \mathrm{GHz}$ (Q-band) were collected with Bruker ELEXSYS E-580 and Varian E-110 EPR spectrometers, respectively. The powder measurements were performed at Q- and X-bands at $\mathrm{T}=300 \mathrm{~K}$. The spectra of a single crystal were measured at Q-band and $\mathrm{T}=300 \mathrm{~K}$ as a function of magnetic field orientation. The temperature variation of a single crystal signal was measured for a fixed field orientation in the temperature range $40 \leq \mathrm{T} \leq 295 \mathrm{~K}$ at $\mathrm{X}$-band, using a liquid helium cryostat.

\section{Computational tools}

Simulations and fitting a convenient spin-hamiltonian to the EPR spectra were made with EasySpin, ${ }^{12}$ a program 
<smiles>O=C([O-])c1ccccc1Nc1cccc(C(F)(F)F)c1</smiles>

Flufenamate

(a)

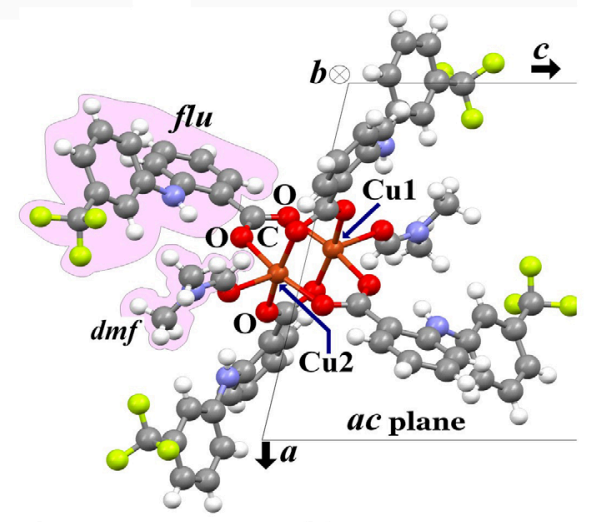

$b \uparrow$

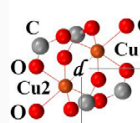

$0 \odot 0^{\circ}$

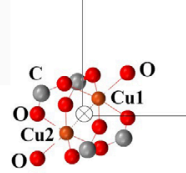

(b)

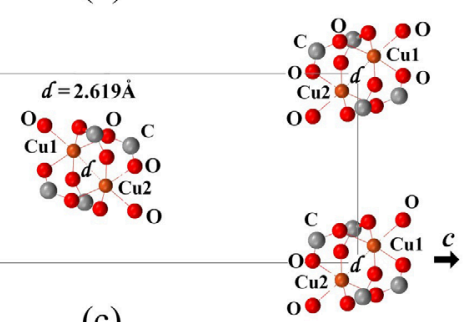

(c)
Figure 1. (a) The flufenamate (flu) anion. (b) View of the $\left[\mathrm{Cu}_{2}(\mathrm{flu})_{4}(\mathrm{dmf})_{2}\right]$ molecule along the $b$ axis (figure generated with data from reference 9). The flu anion and the dmf molecule in the left hand side are emphasized. (c) Arrangement of the dinuclear units in the crystal. The shortest distance between neighbor rotated dinuclear units is $14.24 \AA$.

package working under MATLAB. ${ }^{13}$ The Cambridge Crystallographic Database ${ }^{4}$ and the crystal structure visualization program Mercury ${ }^{14}$ were used along this work.

\section{Results and Discussion}

\section{Magnetic results and analysis}

The molar magnetic susceptibility data $\chi(\mathrm{T})$ are displayed in Figure 2, after subtracting the diamagnetic contribution calculated by standard methods. ${ }^{2}$

Above $c a .80 \mathrm{~K} \chi(\mathrm{T})$ is characteristic of an antiferromagnetically coupled dinuclear unit, with $\chi(\mathrm{T})$ showing a maximum at $\mathrm{T}_{\max } c a .250 \mathrm{~K}$ and decreasing above and below $\mathrm{T}_{\max }$. Below $c a .70 \mathrm{~K} \chi(\mathrm{T})$ increases again with decreasing $\mathrm{T}$, due to traces of paramagnetic mononuclear $\mathrm{Cu}^{\mathrm{II}}$ spins that become important at low $\mathrm{T}^{2}$ When the exchange coupling between $\mathrm{Cu}^{\mathrm{II}}$ ions with spins

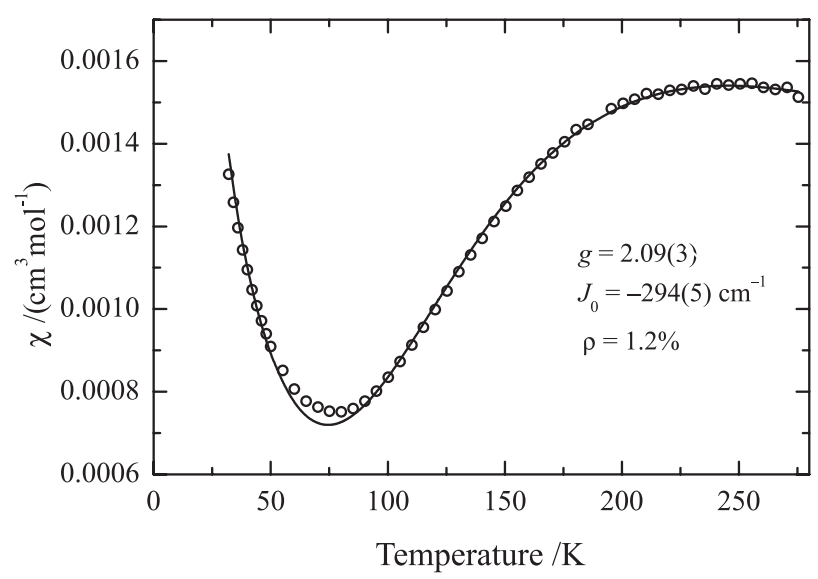

Figure 2. Temperature dependence of the molar magnetic susceptibility $\chi(T)$. Circles are experimental results. Solid lines are obtained fitting equation 2 to the data (parameters given in the text).

$\mathbf{S}_{1}$ and $\mathbf{S}_{2}$ in a dinuclear unit is defined as $\mathcal{H}_{\mathrm{ex}}=-J_{0} \boldsymbol{S}_{1} \cdot \boldsymbol{S}_{2}$, the magnetic susceptibility for a mol of units is given by: ${ }^{1,2}$

$\chi_{0}(T)=\frac{2 N_{\mathrm{Av}} g^{2} \mu_{B}^{2}}{k_{\mathrm{B}} T\left[3+\exp \left(-J_{0} / k_{\mathrm{B}} T\right)\right]}$

where $\mathrm{N}_{\mathrm{Av}}, \mathrm{k}_{\mathrm{B}}$ and $\mu_{\mathrm{B}}$ are the Avogadro's number, Boltzmann's constant and Bohr magneton, respectively, and $g$ is the angular averaged g-factor of $\mathrm{Cu}^{\mathrm{II}}$ ions in dinuclear units. Since there are traces of paramagnetic mononuclear $\mathrm{Cu}^{\mathrm{II}}\left(\rho=\right.$ [number of $\mathrm{Cu}^{\mathrm{II}}$ ions in mononuclear sites]/ [number of $\mathrm{Cu}^{\mathrm{II}}$ ions in dinuclear sites]), their contribution to equation 1 is important and should be considered to evaluate $\chi(\mathrm{T}):^{2}$

$\chi(T)=(1-\rho) \chi_{0}(T)+\rho \frac{N_{\mathrm{Av}} g^{2} \mu_{\mathrm{B}}^{2}}{2 k_{\mathrm{B}} T}$

where we approximate the g-factor of the mononuclear component as equal to that of copper(II) in dinuclear units. Fitting equation 2 to the data in Figure 2 we obtained:

$\mathrm{g}=2.09 \pm 0.03, J_{0}=(-294 \pm 5) \mathrm{cm}^{-1}$ and $\rho=0.012$

The values of $\chi(T)$ calculated with these parameters and equation 2 agree well with the data (see solid line in Figure 2). The contribution of the mononuclear impurities introduces an uncertainty in the g-value of the units, but this is less relevant in evaluating $J_{0}$.

\section{EPR results}

Figures $3 a$ and $3 b$ display as solid lines the EPR spectra of powder samples of $\left[\mathrm{Cu}_{2}(\mathrm{flu})_{4}(\mathrm{dmf})_{2}\right]$ observed at $\mathrm{Q}$ - and $\mathrm{X}$-bands at room temperature. The magnetic fields at the 
peaks of these spectra correspond to the extremes of the line position variations with the magnetic field orientation. We use the standard notation $\mathrm{B}_{\mathrm{z}_{1}}, \mathrm{~B}_{z_{2}}, \mathrm{~B}_{\perp_{1}}$ and $\mathrm{B}_{\perp_{2}}$ for the fields of the peaks of a unit having axial symmetry, ${ }^{15,16}$ corresponding to the positions of the two allowed peaks (1 and 2) observed for $B_{0}$ along the symmetry axis $\left(B_{z}\right)$ and in the perpendicular plane $\left(\mathrm{B}_{\perp}\right)$ of the dinuclear unit. Above $600 \mathrm{mT}$ the Q-band spectrum in Figure 3a displays the strong peaks $\mathrm{B}_{\perp_{1}}$ and $\mathrm{B}_{\perp_{2}}$ and the weaker peaks $\mathrm{B}_{\mathrm{z}_{1}}$, DQ and $\mathrm{B}_{\mathrm{z}_{2}}$ (hidden by the stronger $\mathrm{B}_{\perp_{2}}$ peak). The peak $\mathrm{DQ}$ is the transition between the $M_{S}= \pm 1$ components of the triplet state with the absorption of two microwave quanta. ${ }^{17,18}$ Around $500 \mathrm{mT}$, the weak one-quantum forbidden transition $\mathrm{M}_{\mathrm{S}}= \pm 1 \leftrightarrow \mp 1$ displays a resolved hyperfine pattern (Figure 3a). The room temperature $\mathrm{X}$-band powder spectrum (Figure $3 b$ ) displays the strong $\mathrm{B}_{\perp_{2}}$ peak and the weaker $B_{z_{2}}$ peak above $200 \mathrm{mT}$, as well as a peak around $310 \mathrm{mT}$ (g ca. 2.1-2.3) that corresponds to the superposition of the DQ signal and that of traces of mononuclear species in the sample (M). At X-band the $\mathrm{B}_{\perp_{1}}$ peak is not observed and the $B_{z_{1}}$ peak could not be unambiguously assigned because it overlaps the one-quantum forbidden transition $\Delta \mathrm{M}_{\mathrm{S}}= \pm 2$. Both spectra exhibit the resonance corresponding to the $\mathrm{MgO}: \mathrm{Cr}^{\mathrm{III}}$ marker (Figures $3 \mathrm{a}$ and $3 \mathrm{~b}$ ).

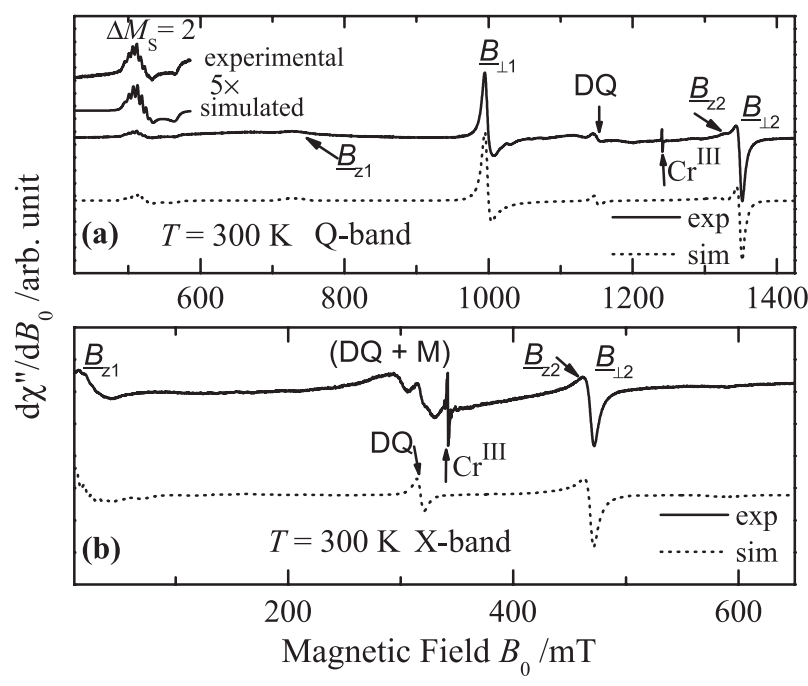

Figure 3. Room temperature EPR spectra $\left(\mathrm{d} \chi " / \mathrm{d} B_{0}\right)$ of powder samples of $\left[\mathrm{Cu}_{2}(\mathrm{flu})_{4}(\mathrm{dmf})_{2}\right]$ at (a) Q and (b) X bands. Solid and dotted lines are experimental results and simulations respectively (see text).

In single-crystal samples, each unit gives rise to the two allowed transitions, $\mathrm{M}_{\mathrm{S}}= \pm 1 \leftrightarrow 0$, and one forbidden transition $\mathrm{M}_{\mathrm{S}}= \pm 1 \leftrightarrow \mp 1$ at low field. So, six resonances arise from the two rotated units for most magnetic field orientations. Selected $\mathrm{d} \chi " / \mathrm{dB}_{0}$ vs. $\mathrm{B}_{0}$ spectra observed at Q-band at different orientations of $\mathrm{B}_{0}$ in the $b c$ plane at $300 \mathrm{~K}$ (solid lines in Figures $4 \mathrm{a}-\mathrm{e}$ ) reflect these characteristics. In the $b c$ plane hyperfine structure is observed in the forbidden resonance at $c a .510 \mathrm{mT}$ (Figure 4a) and in the low field allowed resonance at $c a .800 \mathrm{mT}$ (Figures $4 \mathrm{~b}-\mathrm{e}$ ). The results in the $a^{*} b$ plane (not shown) are similar to those in the $b c$ plane, but the resolution is poorer and the hyperfine structure is lost. The two units are magnetically equivalent for $\mathrm{B}_{0}$ in the $a^{*} c$ plane, where only three resonances are observed. The observed single crystal spectra also exhibit the narrow peak corresponding to the $\mathrm{Cr}^{\text {III }}$ marker (see horizontal arrows) but do not show the DQ transition at $\mathrm{g} c a \cdot 2 \cdot{ }^{17-19}$ This transition is more isotropic than the allowed transitions and thus it is enhanced in the powder spectra.

Positions and widths of each resonance were calculated by fitting the observed peaks to gaussian line shapes. The

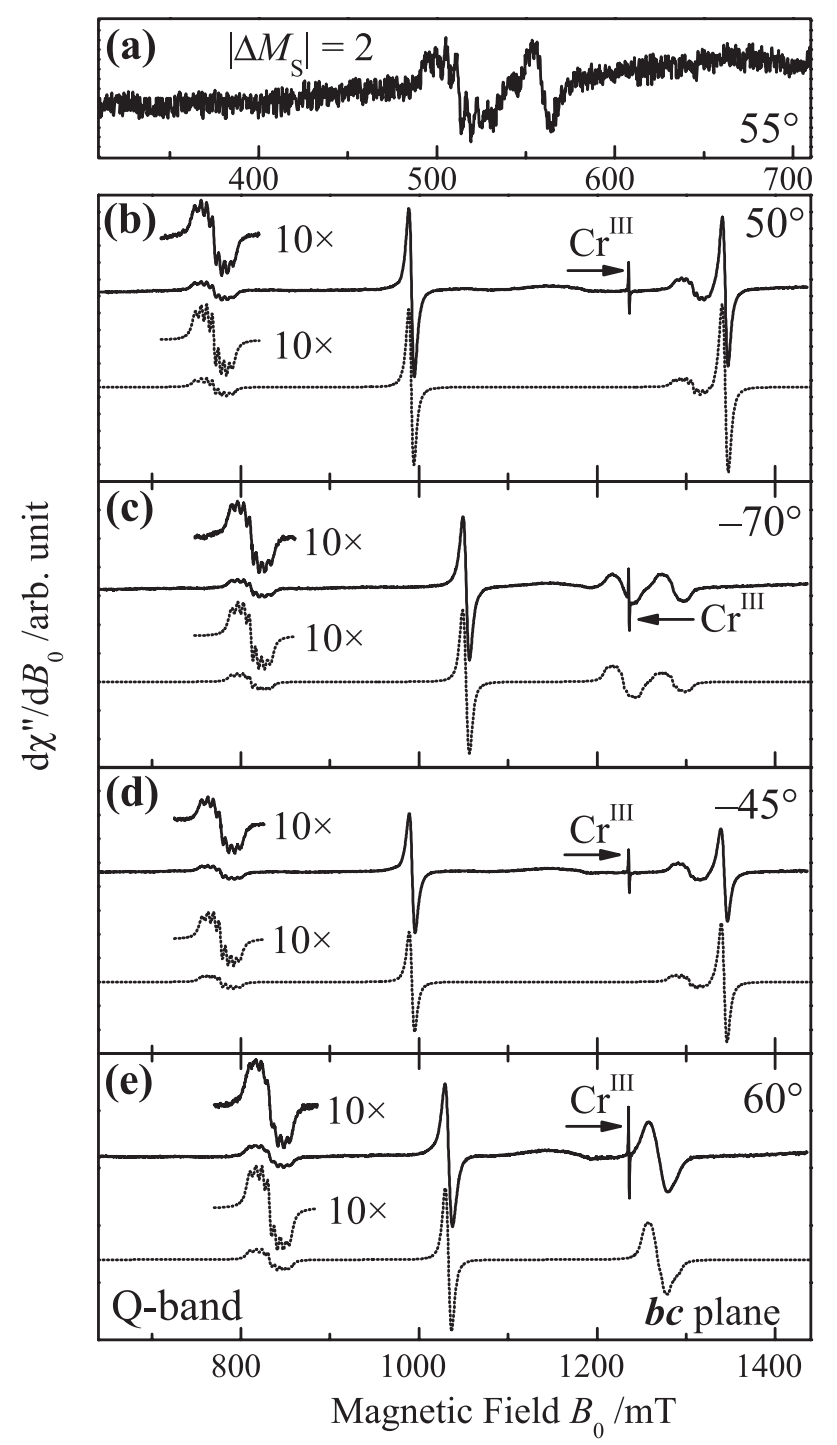

Figure 4. Experimental (solid lines) and simulated (dotted lines) spectra (d $\chi / / \mathrm{dB}_{0}$ ) of single-crystal samples of $\left[\mathrm{Cu}_{2}(\mathrm{flu})_{4}(\mathrm{dmf})_{2}\right]$ at Q-band and $300 \mathrm{~K}$. (a) Weak one-quantum forbidden transition $\mathrm{M}_{\mathrm{S}}= \pm 1 \leftrightarrow \mp 1$ at 510 and $560 \mathrm{mT}$. (b), (c), (d) and (e): Spectra in the field range 650-1430 $\mathrm{mT}$ in the $b c$ plane for selected angles $\phi$ of the magnetic field $\mathrm{B}_{0}$ with the $c$ axis. 


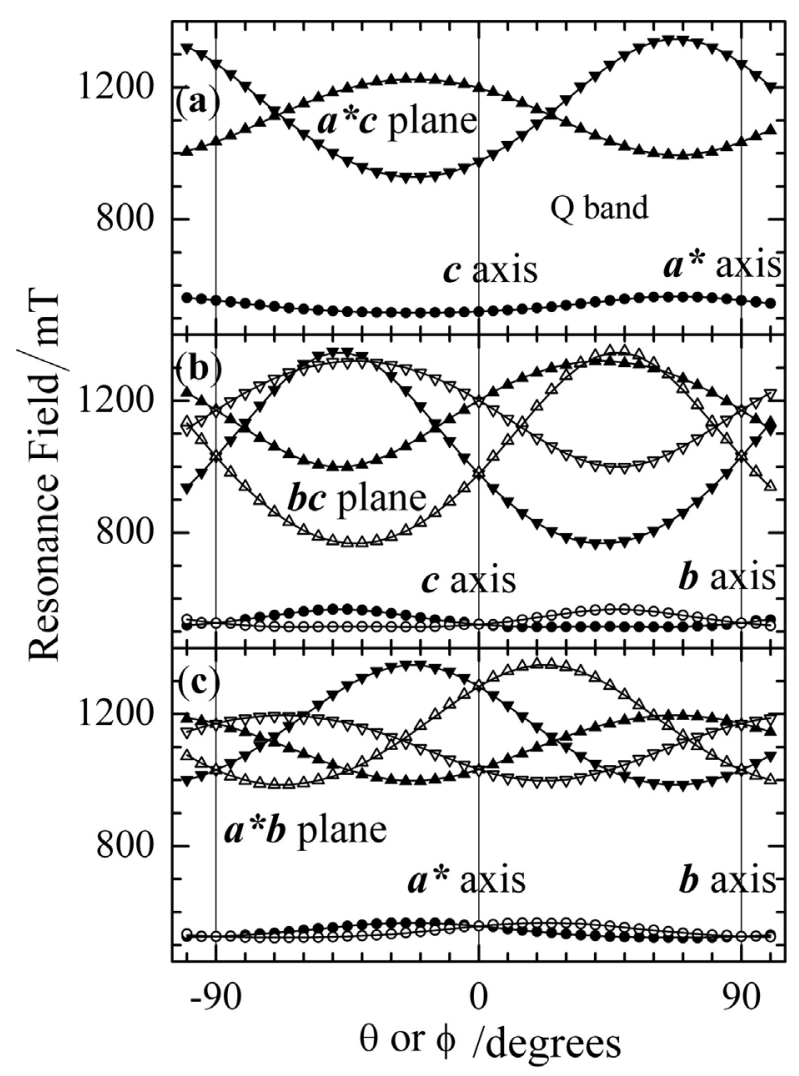

Figure 5. Field positions of the resonances corresponding to dinuclear units A (empty symbols) and B (filled symbols) observed at $34.5 \mathrm{GHz}$ and $\mathrm{T}=298 \mathrm{~K}$ as a function of the orientation of $\mathrm{B}_{0}$ in the planes: (a) $a^{*} c$, (b) $b c$, and (c) $a^{*} b$ of a single crystal sample. Triangles indicate the $\mathrm{M}_{\mathrm{s}}= \pm 1 \rightarrow 0$ transitions, circles represent the "forbidden" resonance with $\left|\Delta \mathrm{M}_{\mathrm{S}}\right|=2$. The solid lines were drawn from the parameters obtained using EasySpin ${ }^{12}$ given in the text.

angular variations of these positions observed in the planes $a^{*} c, b c$ and $a^{*} b$ are displayed in Figure 5 where empty and filled symbols correspond to units A and B, respectively.

Selected single crystal spectra collected at X-band and $40<\mathrm{T}<295 \mathrm{~K}$ for the field orientation in the $a^{*} c$ plane, where the single allowed resonance appears at the highest field $\left(\mathrm{B}_{0} c a .470 \mathrm{mT}\right)$ and does not overlap with the resonances of the $\mathrm{Cr}^{\mathrm{III}}$ marker and the mononuclear species, are displayed in Figure 6a. At $40 \mathrm{~K}$ no signals arising from the dinuclear units appear. In Figure $6 \mathrm{~b}$ the spectrum (1) displays $\mathrm{d} \chi " / \mathrm{d} B_{0}$ observed at $180 \mathrm{~K}$; its baseline is corrected in the spectrum (2) and its integral is displayed in (3). The areas of the peaks corresponding to the dinuclear species $\left(\mathrm{A}_{\mathrm{Cu}}\right.$ II) and to the $\mathrm{Cr}$ III marker $\left(\mathrm{A}_{\mathrm{Cr}}\right.$ III) were calculated at each $\mathrm{T}$ from Figure $6 \mathrm{~b}-3$ and the ratio $\mathrm{R}=\mathrm{A}_{\mathrm{Cu}}{ }^{\mathrm{II}} / \mathrm{A}_{\mathrm{Cr}}{ }_{\mathrm{III}}$ of these areas is plotted in Figure 7 as a function of temperature.

\section{Analysis of the EPR results}

The EPR spectra of isolated dinuclear units have been discussed in textbooks, ${ }^{17-20}$ and we analyzed our
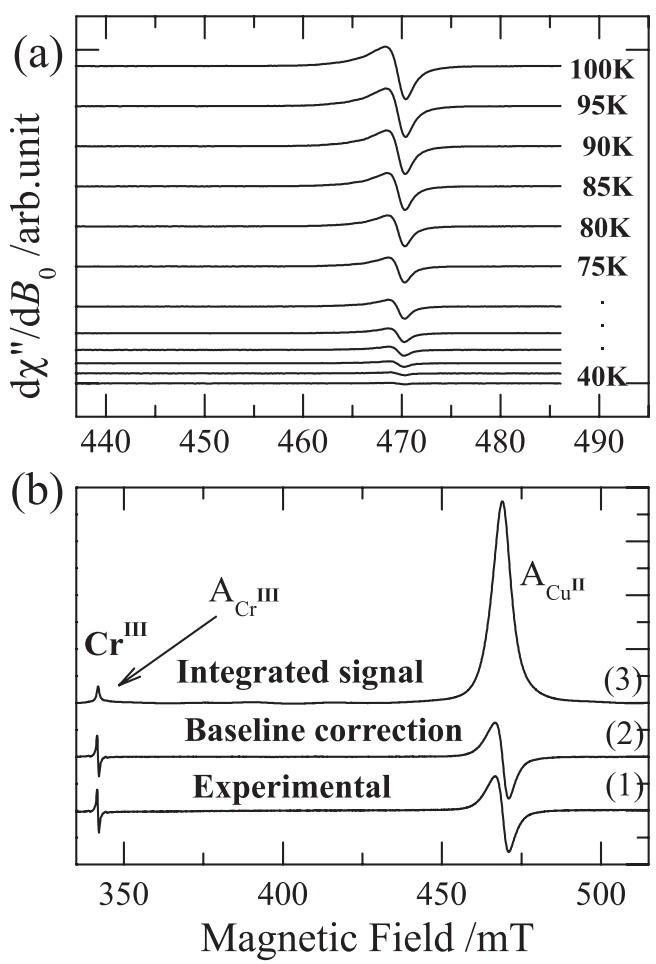

Figure 6. (a) Selected X-band single crystal EPR spectra observed in the range $40 \leq \mathrm{T} \leq 295 \mathrm{~K}$ for a special orientation in the $a * c$ plane (see text). (b) Wider field sweep showing together the peak of the dinuclear unit and that of the $\mathrm{Cr}^{\mathrm{III}}$ marker at $180 \mathrm{~K}$. (1) Observed spectrum (d $\chi$ "/d $\left.B_{0}\right)$. (2) Observed spectrum with a baseline correction. (3) Integral of the spectrum (2), allowing calculating the areas of the two peaks, $\mathrm{A}_{\mathrm{Cu}}$ and $\mathrm{A}_{\mathrm{Cr}}$, and the normalized intensity ratio $\mathrm{R}=\mathrm{A}_{\mathrm{CuI}} / \mathrm{A}_{\mathrm{CrIII}}$ as a function of $\mathrm{T}$.

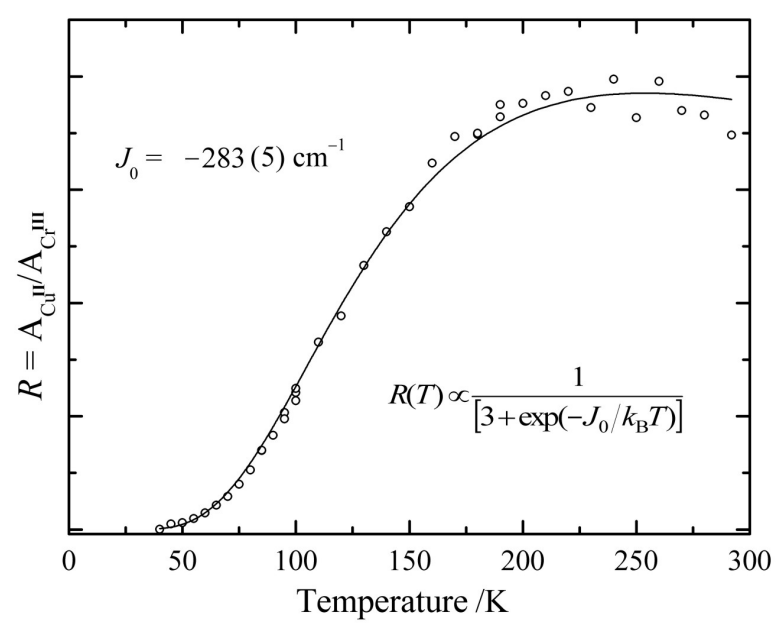

Figure 7. Normalized intensity ratio $\mathrm{R}$ between the areas of the integrated single crystal peak of the dinuclear unit and that of the peak corresponding to the $\mathrm{MgO}: \mathrm{Cr}^{3+}$ marker (see Figure 6), as a function of temperature. Symbols are experimental results; the solid line represents the best fit of equation 8 to the data.

data in powder and single crystals as described in recent publications. ${ }^{6,8,21}$ When the couplings between $\mathrm{Cu}^{\mathrm{II}}$ ions in neighbor units are negligible, the EPR spectra of a unit is described by the spin hamiltonian: 


$$
\mathcal{H}_{0}=\mathcal{H}_{\text {ex }}+\mathcal{H}_{\text {anis }}+\mathcal{H}_{\mathrm{Z}}+\mathcal{H}_{\text {hiper }}
$$

The anisotropic spin-spin interaction $\mathcal{H}_{\text {anis }}$ between $\mathrm{S}_{1}$ and $\mathrm{S}_{2}$ is described by a matrix $\mathscr{D}_{\mathrm{A}}$ as:

$$
\mathcal{H}_{\text {anis }}=S_{1} \cdot \mathcal{D}_{\mathrm{A}} \cdot S_{2}
$$

and, since the g-matrices $\mathrm{g}_{1}=\mathrm{g}_{2}$ for units having an inversion center, the Zeeman coupling $\mathcal{H}_{\mathrm{Z}}$ is:

$\mathcal{H}_{\mathrm{Z}}=\mu_{\mathrm{B}} \mathrm{B}_{0} \cdot \mathrm{g}_{1} \cdot S_{1}+\mu_{\mathrm{B}} \mathrm{B}_{0} \cdot \mathrm{g}_{2} \cdot S_{2}=\mu_{\mathrm{B}} \mathrm{B}_{0} \cdot \mathrm{g}_{\mathrm{A}} \cdot\left(\boldsymbol{S}_{1}+S_{2}\right)$

The hyperfine coupling $\mathcal{H}_{\text {hiper }}$ between electronic and nuclear spins $\left(\mathrm{I}_{1}\right.$ and $\left.\mathrm{I}_{2}\right)$ is described by an $\mathcal{A}$ matrix as:

$$
\mathcal{H}_{\text {hiper }}=S_{1} \cdot \mathcal{A} \cdot I_{1}+S_{2} \cdot \mathcal{A} \cdot I_{2}
$$

With the transformations $\mathrm{S}_{\mathrm{A}}=\mathrm{S}_{1}+\mathrm{S}_{2},\left(\mathrm{~S}_{\mathrm{A}}=1,0\right)$, and $I_{A}=I_{1}+I_{2},\left(I_{A}=3,2,1,0\right)$, of the electronic and nuclear spin operators for the unit $\mathrm{A}$, one arrives to: ${ }^{17-19}$

$\mathcal{H}_{0}(\mathrm{~A})=\mu_{\mathrm{B}} \mathrm{B}_{0} \cdot \mathrm{g}_{\mathrm{A}} \cdot S_{\mathrm{A}}-1 / 2 J_{0} S_{\mathrm{A}}\left(S_{\mathrm{A}}+1\right)+S_{\mathrm{A}} \cdot \mathrm{D}_{\mathrm{A}} \cdot S_{\mathrm{A}}+S_{\mathrm{A}} \cdot \mathrm{A}_{\mathrm{A}} \cdot \boldsymbol{I}_{\mathrm{A}}$

where the $S_{A}=1$ triplet state giving rise to the EPR signal has a g-matrix $\mathrm{g}_{\mathrm{A}}$ and zero field splitting and hyperfine interaction matrices $\mathrm{D}_{\mathrm{A}}=\mathscr{D} / 4$ and $\mathrm{A}_{\mathrm{A}}=\mathcal{A} / 2$. The spectra and the matrices ${ }^{22} \mathrm{~g}_{\mathrm{B}}, \mathrm{D}_{\mathrm{B}}$ and $\mathrm{A}_{\mathrm{B}}$ for units type $\mathrm{B}$ are obtained by a $\mathrm{C}_{2}$ rotation around $b$ of the spectra and matrices for units type $\mathrm{A}$. Assuming units having axial symmetry, the powder and single-crystal spectra predicted by equation 7 can be simulated in terms of five spin Hamiltonian parameters: two principal values of $g_{A}, g_{/ /}$and $g_{\perp}$, the axial principal value $D$ of the $D_{A}$ matrix, plus two principal values of the A-matrix, $A_{/ /}=A_{z z}$ and $A_{\perp}$ (along and perpendicular to the $\mathrm{Cu}-\mathrm{O}$ bonds, respectively). This approximation assumes the same principal axes for the matrices $\mathrm{g}, \mathrm{D}$ and $\mathrm{A}$ (see later). Ozarowski proved that $\mathrm{D}$ is negative for tetracarboxylate $\mathrm{Cu}^{\text {II }}$ "paddle wheel" dinuclear units. ${ }^{23}$

Simultaneous least squares optimization of powder spectra simulations at $\mathrm{Q}$ and $\mathrm{X}$ bands, shown in dotted lines in Figures $3 a$ and $3 b$, allowed obtaining the spin Hamiltonian parameters

$$
\begin{gathered}
\mathrm{g}_{/ /}=2.373 \pm 0.004, \mathrm{~g}_{\perp}=2.073 \pm 0.004 \\
\mathrm{D}=(-0.334 \pm 0.001) \mathrm{cm}^{-1} \text { and } \mathrm{E} \text { ca. } 0
\end{gathered}
$$

The variation of the position of the resonances observed with the orientation of $\mathrm{B}_{0}$ in single crystal samples (Figure 5) allows obtaining the parameters involved in the matrices $g_{A}, D_{A}$ and $A_{A}$ using EasySpin. The hyperfine coupling parameters $\mathrm{A}_{/ /}$and $\mathrm{A}_{\perp}$ obtained from the single crystal spectra in Figures $4 \mathrm{~b}$-e were used to simulate the powder spectra and reproduce well the hyperfine structure of the low field region. These results do not reproduce the double-quantum transition DQ (personal communication of S. Stoll to O. R. Nascimento), which was then calculated following reference 8 and added to the simulation. The M peak does not appear in the simulated spectra of the units.

Least squares fits of the angular variation of the single crystal resonances (Figures 5a-c) allowed evaluating g-factors and D parameter in excellent agreement with the result obtained for the powder sample. The hyperfine parameters

$$
\mathrm{A}_{/ /}=(70 \pm 10) \times 10^{-4} \mathrm{~cm}^{-1} \text { and } \mathrm{A}_{\perp}=(2 \pm 1) \times 10^{-4} \mathrm{~cm}^{-1}
$$

were calculated from simulations of the structure resolved around $800 \mathrm{mT}$ along some field directions in the $b c$ plane (Figures 4b-e), and used to simulate the hyperfine splitting in the powder spectra (see Figures $3 \mathrm{a}$ and $3 \mathrm{~b}$ ), in good agreement with the data.

The exchange parameter $J_{0}$ was obtained from the variation with $\mathrm{T}$ of the EPR signal intensity of the dinuclear unit (Figures 6a and 6b). ${ }^{24}$ The ratio $\mathrm{R}$ between the areas of the peak of the single crystal spectra and the peak corresponding to the marker (Figure 6) is displayed in Figure 7 as a function of T. For antiferromagnetically coupled units, $\mathrm{R}(\mathrm{T})$ follows: ${ }^{24}$

$$
R(T) \propto \frac{1}{\left[3+\exp \left(-J_{0} / k_{\mathrm{B}} T\right)\right]}
$$

and we obtained $J_{0}=(-283 \pm 5) \mathrm{cm}^{-1}$ from a least-squares fit of equation 8 to the data included as a solid line in Figure 7. Measuring the variation with $\mathrm{T}$ of a single crystal EPR signal (instead of a peak of the powder spectra) avoids errors arising from contribution of the mononuclear impurities whose resonance may partially overlap the dinuclear peak. Our method also corrects changes in the intensity of the signal arising from changes of the microwave cavity with temperature.

The results in Figures 5a-c do not display collapses of the $\mathrm{M}_{\mathrm{S}}= \pm 1 \leftrightarrow 0$ resonances corresponding to dinuclear units $\mathrm{A}$ and $\mathrm{B}$ for magnetic field orientations near the magic angles, as observed by Napolitano et al. ${ }^{8}$ in the dinuclear compound $\left[\mathrm{Cu}_{2}(\mathrm{TzTs})_{4}\right]$ having copper(II) ions in dinuclear units. Since our experimental setup allows accurate measurements at angular intervals of $1^{\circ}$, the angular variation of the spectra in Figure 5 allows estimating a higher limit $\left|J^{\prime}\right|<5 \times 10^{-3} \mathrm{~cm}^{-1}$ for these interdinuclear interactions. 


\section{Discussion}

The difference between the values of $J_{0}$ obtained from the temperature variation of the susceptibility $\left(J_{0}=(-294 \pm 5) \mathrm{cm}^{-1}\right)$ and of the EPR line intensities $\left(J_{0}=(-283 \pm 5) \mathrm{cm}^{-1}\right)$ may arise from the presence of traces of mononuclear centers contributing to the magnetic properties measured by these two techniques at low T. ${ }^{2}$ However, these contributions from the temperature variation of the EPR line intensities are much less important because the single crystal peaks corresponding to dinuclear units do not overlap the peaks due to mononuclear impurities at the studied field orientations. ${ }^{6}$ This is clearly evidenced comparing Figures 3 and 7 below $70 \mathrm{~K}$. Thus, even if the difference between the values is small, we attribute a better quality to the EPR result.

The main factors determining $J_{0}$ are the crystal geometry and the electronic structures of the $\mathrm{Cu}-\mathrm{O}-\mathrm{C}-\mathrm{O}-\mathrm{Cu}$ bridges. The unpaired electrons of the $\mathrm{Cu}^{\mathrm{II}}$ ions interact through the bridging ligands and the super exchange interaction is usually described by natural magnetic orbitals, ${ }^{2}$ that for the $\mathrm{Cu}$ atoms in the cage structure are constructed from $\mathrm{d}_{\mathrm{x}^{2}-\mathrm{y}^{2}}$ copper orbitals with tails extending through the bridges. Changes of the geometry of the $\mathrm{Cu}-\mathrm{O}-\mathrm{C}-\mathrm{O}-\mathrm{Cu}$ bridges vary the overlap between $\mathrm{Cu} \mathrm{d}_{x^{2}-y^{2}}$ and $\mathrm{O} 2 \mathrm{p}_{\mathrm{x}}$ orbitals, which in turn produce variations of $J_{0}{ }^{2}$ So, for "paddle wheel" units described by $\left[\mathrm{Cu}_{2}(\mu-\mathrm{OOCR})_{4} \mathrm{~L}_{2}\right]$, the $\mathrm{R}$ groups are most important in changing the electronic structure of the bridges, but the L groups may vary structural constraints, changing local symmetry and bond geometry at the dinuclear unit, producing geometrical differences between the structures of the four $\mathrm{O}-\mathrm{C}-\mathrm{O}$ bridges. Therefore, even if a value $\left|J_{0}\right| c a \cdot 280-300 \mathrm{~cm}^{-1}$ is a good guess for all tetracarboxylate "paddle wheel" copper(II) dinuclear units, ${ }^{2}$ explaining the small differences that may occur for different cases requires a detailed analysis of the symmetry and dimensions of the units, that may change from case to case.

The zero field splitting of the excited triplet state of the dinuclear unit, characterized by the parameter $\mathrm{D}=(-0.334 \pm 0.001) \mathrm{cm}^{-1}=(-10.01 \pm 0.03) \mathrm{GHz}$ for $\left[\mathrm{Cu}_{2}(\mathrm{flu})_{4}(\mathrm{dmf})_{2}\right]$ arises from dipole-dipole interactions between the two $\mathrm{Cu}^{\mathrm{II}}$ spins at $2.619 \AA$ and from anisotropic components of the exchange coupling. A straightforward calculation in the point dipolar approximation ${ }^{25,26}$ gives $\left|D_{\text {point-dip }}\right|=-0.19 \mathrm{~cm}^{-1}$. However, considering the spatial distribution of the unpaired electron (instead of the point charge approximation), this point charge value should be taken as a lower limit. This allows inferring a higher limit for the anisotropic exchange contribution, $\left|D_{\text {anis. exch }}\right|<0.14 \mathrm{~cm}^{-1}$, (where $D_{\text {anis. exch }}$ should be negative). Among the large quantity of $\mathrm{Cu}^{\mathrm{II}}$ compounds involving tetracarboxylate "paddle wheel" units reviewed by
Melník et al., ${ }^{7}$ some of them involve dinuclear units bridged by flu ligands. ${ }^{10}$ The parameter $D$ evaluated for $\left[\mathrm{Cu}_{2}(\mathrm{flu})_{4}\left(\mathrm{H}_{2} \mathrm{O}\right)_{2}\right]^{10}$ is nearly identical to that obtained here for $\left[\mathrm{Cu}_{2}(\mathrm{flu})_{4}(\mathrm{dmf})_{2}\right]$. EPR studies of other copper flufenamates ${ }^{10}$ of the $\left[\mathrm{Cu}_{2}(\mathrm{flu})_{4}(\mathrm{~L})_{2}\right]$ type with several $\mathrm{L}$ ligands display similar behavior. This is different for compounds of the $\left[\mathrm{Cu}_{2}(\mathrm{flu})_{4}\left(\mathrm{~L}_{1}\right)\left(\mathrm{L}_{2}\right)\right]$ type, which display distinct EPR spectra, and magnetic studies are needed for a complete characterization.

The hyperfine coupling parameters of the $\mathrm{Cu}^{\mathrm{II}}$ ions in $\left[\mathrm{Cu}_{2}(\mathrm{flu})_{4}(\mathrm{dmf})_{2}\right]$ given above (equation 7 ) are about half the values observed for mononuclear $\mathrm{Cu}^{\mathrm{II}}$ ions, ${ }^{11,27,28}$ as expected for dinuclear units.

Considering the results in reference 8 we estimated an upper limit $\left|J^{\prime}\right| \leq 5 \times 10^{-3} \mathrm{~cm}^{-1}$ for the magnitude of the exchange coupling between neighbor rotated dinuclear units types $\mathrm{A}$ and $\mathrm{B}$ in $\left[\mathrm{Cu}_{2}(\mathrm{flu})_{4}(\mathrm{dmf})_{2}\right]$, considering the single crystal spectra measured in the $a^{*} b$ and $b c$ planes. They correspond to interactions between $\mathrm{Cu}^{\mathrm{II}}$ ions at $c a$. $14.24 \AA$, transmitted through a long and complicate exchange path (Figure 1c) that involves 12 atoms in sigma bonds plus a weak electrostatic contact between a methyl group of a dmf molecule and the trifluoromethylphenyl ring of a flu ligand in a neighbor rotated molecule separated by $c a$. $4.3 \AA$. This value may be compared with $6 \times 10^{-3} \mathrm{~cm}^{-1}$ between $\mathrm{Cu}^{\mathrm{II}}$ ions at $c a$. $15.7 \AA$ connected by a path containing $9 \sigma$-bonds plus $2 \mathrm{H}$-bonds, ${ }^{29}$ and with $c a .3 \times 10^{-3} \mathrm{~cm}^{-1}$ between two quinone radicals at $17.2 \AA$ connected by a path containing $7 \sigma$-bonds plus $2 \mathrm{H}$-bonds. ${ }^{30,31}$ Evaluating weak couplings between well separated spins or polynuclear units is interesting from the point of view of molecular magnetism because they determine the magnetic isolation. They are also interesting because of being related to the matrix elements of electron transfer between unpaired electrons. ${ }^{30}$ Unfortunately, only an upper limit of this coupling can be obtained for $\left[\mathrm{Cu}_{2}(\mathrm{flu})_{4}(\mathrm{dmf})_{2}\right]$.

\section{Conclusions}

We report detailed EPR and magnetic investigations of the compound $\left[\mathrm{Cu}_{2}(\mathrm{flu})_{4}(\mathrm{dmf})_{2}\right]$ having $\mathrm{Cu}^{\mathrm{II}}$ ions in centrosymmetric dinuclear units with "paddle wheel" geometry. The exchange coupling $J_{0}=(-283 \pm 4) \mathrm{cm}^{-1}$ between copper ions in the dinuclear units, obtained from the temperature variation of the EPR intensities in an oriented single crystal, is more accurate than that obtained from the most common measurements of the $T$ variation of the susceptibility, where uncertainties introduced by mononuclear copper impurities cannot be avoided.

We also obtained the fine structure parameters $\mathrm{D}=(-0.334 \pm 0.001) \mathrm{cm}^{-1}$ and $\mathrm{E} c a$. 0 from the EPR data, 
which reflect a high degree of axial symmetry of the units and are a consequence of dipole-dipole and anisotropic exchange couplings between $\mathrm{Cu}^{\mathrm{II}}$ ions. We also estimated from the EPR data a lower limit $\left|J^{\prime}\right| \leq 5 \times 10^{-3} \mathrm{~cm}^{-1}$ for the interaction between neighbor dinuclear units in the lattice. Obtaining information about this type of couplings between spin clusters is relevant, because they characterize their magnetic isolation, an important parameter in molecular magnetism. ${ }^{6,8}$ The origin of these parameters has been discussed along the text, and we conclude that, when possible, detailed single crystal EPR measurements provide the most complete source of information about the properties of spin clusters. They allow evaluating extremely weak exchange interactions, even in the presence of much stronger magnetic couplings. ${ }^{32}$

\section{Acknowledgments}

This work was supported by PRONEX/FAPESP/CNPq (grant 2003/09859-2) in Brazil and by CAI+D (UNL) in Argentina. L. M. B. N. was a PhD fellow from CAPES in Brazil. R. C. is a CONICET researcher.

\section{References}

1. Bleaney, B.; Bowers, K. D.; Proc. Roy. Soc. (London) A 1952, $214,451$.

2. Kahn, O.; Molecular Magnetism, VCH: New York, 1993.

3. Guha, B. C.; Proc. Roy. Soc. (London) A 1951, 206, 353.

4. Allen, F. H.; Acta Crystallogr., Sect. B: Struct. Sci. 2002, 58, 380.

5. Clérac, R.; Cotton, F. A.; Dunbar, K. R.; Hillard, E. A.; Petruchina, M. A.; Smucker, B. W.; C. R. Acad. Sci. Paris, Chimie 2001, 4, 315.

6. Perec, M.; Baggio, R.; Sartoris, R. P.; Santana, R. C.; Peña, O.; Calvo, R.; Inorg. Chem. 2010, 49, 695.

7. Melník, M.; Kabešová, M.; Koman, M.; Macášková, L.; Garaj, J.; Holloway, C. E;. Valent, A.; J. Coord. Chem. 1998, 45, 147.

8. Napolitano, L. M. B.; Nascimento, O. R.; Cabaleiro, S.; Castro, J.; Calvo, R.; Phys. Rev. B: Condens. Matter Mater. Phys. 2008, $77,214423$.

9. Facchin, G.; Torre, M. H.; Kremer, E.; Piro, O. E.; Baran, E. J.; Z. Anorg. Allg. Chem. 1998, 624, 2025.

10. Melník, M.; Macášková, L.; Mroziński, J.; Polyhedron 1988, 7, 1745; Melník, M.; Potočňak, I.; Macášková, L.; Holloway, C. E.; Mikloš, D., Polyhedron 1996, 15, 2159; Melník, M.; Kohútová, M.; Acta Facult. Pharm. Univ. Comenianae 2009, 56,10 .
11. Brondino, C. D.; Casado, N. M. C.; Passeggi, M. C. G.; Calvo, R.; Inorg. Chem. 1993, 32, 2078.

12. Stoll, S.; Schweiger, A.; J. Magn. Reson. 2006, 178, 42.

13. MatLab, Version 7.1, The MathWorks, Inc., Natick, MA, 01760 , 2007.

14. Bruno, I. J.; Cole, J. C.; Edgington, P. R.; Kessler, M.; Macrae, C. F.; McCabe, P.; Pearson, J.; Taylor, R.; Acta Crystallogr., Sect. B: Struct. Sci. 2002, 58, 389.

15. Wasserman, E.; Snyder, L.C.; Yager, W. A.; J. Chem. Phys. 1964, 41, 1763.

16. Griebel, J.; Leistner, F.; Krautscheid, H.; Kirmse, R.; Z. Anorg. Allg. Chem. 2006, 632, 866.

17. Atherton, N. M.; Principles of Electron Spin Resonance, Ellis Horwood and PTR Prentice Hall, Physical Chemistry Series: New York, 1993.

18. Weil, J. A.; Bolton, J. R.; Wertz, J. E.; Electron Paramagnetic Resonance: Elementary Theory and Practical Applications, Wiley: New York, 1994.

19. Bencini, A.; Gatteschi, D., Electron Paramagnetic Resonance of Exchange Coupled Systems, Springer-Verlag: Berlin, 1990.

20. Pilbrow, J. R.; Transition Ion Electron Paramagnetic Resonance, Clarendon Press: Oxford, England, 1990.

21. Calvo, R.; Rapp, R. E.; Chagas, E.; Sartoris, R. P.; Baggio, R.; Garland, M. T.; Perec, M.; Inorg. Chem. 2008, 47, 10389.

22. Weil, J. A.; EPR Newsletter 2007, 17, 13.

23. Ozarowski, A.; Inorg. Chem. 2008, 47, 9760.

24. Wasson, J. R.; Shyr, C.-I.; Trapp, C.; Inorg. Chem. 1968, 7, 469.

25. Ozarowski, A.; Reinen, D.; Inorg. Chem. 1986, 25, 1704.

26. Schlam, R. F.; Perec, M.; Calvo, R.; Lezama, L.; Insausti, M.; Rojo, T.; Foxman, B. M.; Inorg. Chim. Acta 2000, 310, 81.

27. Vieira, E. D.; Facchin, G.; Torre, M. H.; Costa-Filho, A. J.; J. Braz. Chem. Soc. 2008, 19, 1614.

28. Dalosto, S. D.; Ferreyra, M. G.; Calvo, R.; Piro, O. E.; Castellano, E. E.; J. Inorg. Biochem. 1999, 73, 151.

29. Santana, R. C.; Cunha, R. O.; Carvalho, J. F.; Vencato, I.; Calvo, R.; J. Inorg. Biochem. 2005, 99, 415.

30. Calvo, R.; Abresch, E. C.; Bittl, R.; Feher, G.; Hofbauer, W.; Isaacson, R. A.; Lubitz, W.; Okamura, M. Y.; Paddock, M. L.; J. Am. Chem. Soc. 2000, 122, 7327.

31. Calvo, R.; Isaacson, R. A.; Paddock, M. L.; Abresch, E. C.; Okamura, M. Y.; Maniero, A. L.; Brunel, L. C.; Feher, G.; J. Phys. Chem. B 2001, 105, 4053.

32. Calvo, R.; Appl. Magn. Reson. 2007, 31, 271.

Submitted: June 8, 2010

Published online: December 9, 2010

FAPESP has sponsored the publication of this article. 